\title{
The Effects of Heat and Compression on Moisture Content and Water Absorption of PALF/Sugarcane Bagasse Composition in Disposable Plate Production
}

\author{
Mohammad Sukri Mustapa, a, Saiful Din Sabdin ${ }^{1, b}$, Abdul latif Mohd Tobi ${ }^{1, c}$, \\ Md Saidin Wahab ${ }^{1, d}$, Mohd Radzi Mohamed Yunus ${ }^{1, e}$ and Yusri Yusof ${ }^{1, f}$ \\ ${ }^{1}$ Faculty of Mechanical Engineering, Universiti Teknologi Tun Hussein Onn Malaysia, Batu Pahat, \\ Malaysia.

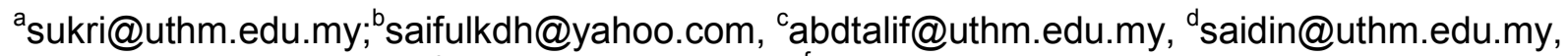 \\ eradzi@uthm.edu.my, fyusri@uthm.edu.my
}

Keywords: Water absorption, Heat compression, Moisture content, Pineapple leaf fibers, Sugarcane bagasse fibers, Disposable plate.

\begin{abstract}
This paper presents the results of heat and compression effects on moisture content and water absorption properties in the manufacturing of disposable plate made from Pineapple Leaf Fiber-based material (PALF). The plate was made of PALF and sugarcane bagasse waste as an alternative to polystyrenes, designed to promote the green technology effort on food packaging material. Two different specimens were produced with different compositions of PALF/sugarcane bagasse series N2T8 ( $20 \mathrm{wt} \%$ of Pineapple leaf fiber and $80 \mathrm{wt} \%$ of sugarcane bagasse ) and series N8T2 ( $80 \mathrm{wt} \%$ of Pineapple leaf fiber and $20 \mathrm{wt} \%$ of sugarcane bagasse). The specimens were produced using a hot press machine set at compressing temperatures of $50^{\circ} \mathrm{C}, 100^{\circ} \mathrm{C}$ and $150^{\circ} \mathrm{C}$ with constant pressure of $0.024 \mathrm{MPa}$ for 10 minutes. Moisture content and water absorption tests were carried out on the specimens to determine the moisture content and water absorption properties. The lower water absorption was obtained for specimen N8T2 because PALF potential to water resistance. This range of properties is expected to be good enough for the requirement of disposable plate and it has the potential as a suitable raw material for strength and lightweight in the manufacturing of disposable plates.
\end{abstract}

\section{Introduction}

Paper plate are ubiquitous since 1904. The extensive researches have been reported on non-wood as nature fibres as alternative fibres sources in production of paper due to the decreasing of wood source and to reduce the pollutions [1-5]. For example of non-wood fibres are wheat [1] and rice [2] straws, sorghum [3] tobacco [4] stalk and banana [5] used as a raw material for pulp and paper production. China uses more than straw and other non-wood as a raw material for paper production [6]. Malaysia interest to agriculture as natural fibers are introduced because they are lower in cost and lower in density as compared to glass fibers [7-8]. Mustapa and co-workers [9] have been done investigated the effect of heat compression on tensile strength in pineapple leaf fibre (PALF) and sugarcane bagasse percentage of paper sheet. The result shows that the increase of heat compression would be beneficial for enhancing the tensile strength. However, the heat and compression effects on moisture content and water absorption in PALF and sugarcane bagasse could be clarified. In the present study, to investigate the process ability of PALF and sugarcane bagasse as a raw material for disposable plate at different heat compression temperatures. The moisture content and water absorption behavior were investigated. 


\section{Material and Methods}

PALF and sugarcane bagasse waste used were collected from a Pineapple farm located in Batu Pahat Johor. Fig. 1(a) shows the schematic of the process used for material preparation and to produce the paper plate. The raw materials of PALF and sugarcane bagasse were cut and washed with water to remove dirt. The materials also was immersed in water mixed with sodium hydroxide with the ratio of $10: 1$. Then the water was heated to $100^{\circ} \mathrm{C}$ within 20 minute and this temperature was maintained for 24 hours. Then, the fiber was removed and blended using commercial blender machine and mixed with sugarcane bagasse at different composition series N8T2 and N2T8 respectively. A mold (34 cm (length) x $34 \mathrm{~cm}$ (Width) x $13 \mathrm{~cm}$ (thick)) and a heat compression machine were used to produce $24 \mathrm{~mm}$ size paper plates as shown in Fig. $1 \mathrm{~b}$, The samples were then dried in an oven at $60{ }^{\circ} \mathrm{C}$ for 24 hours. Fig. 2 shows the sample disposable plates.

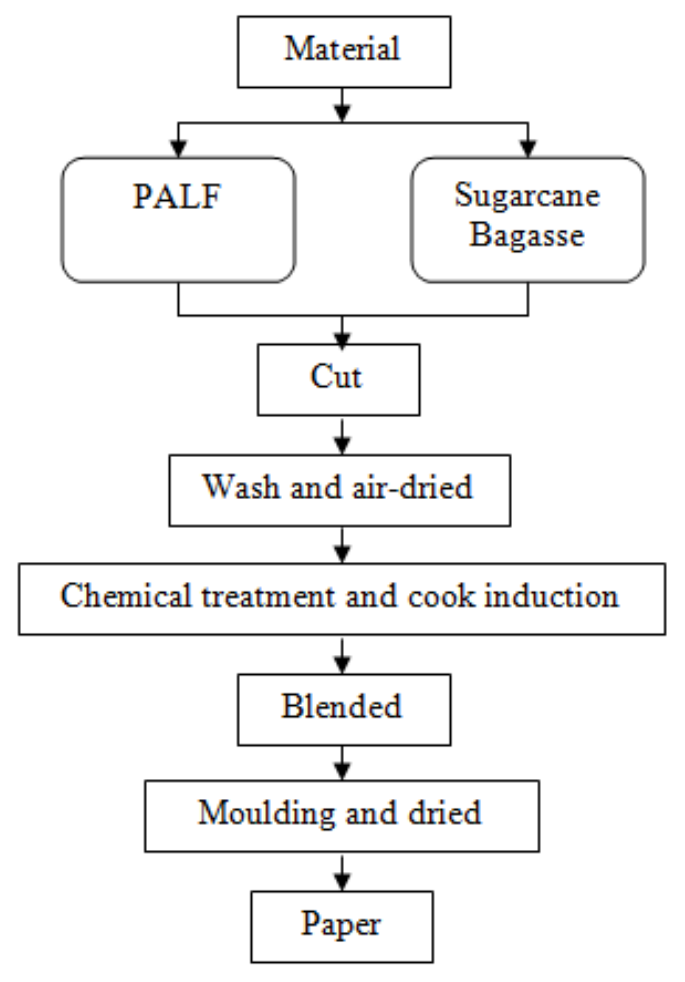

a)

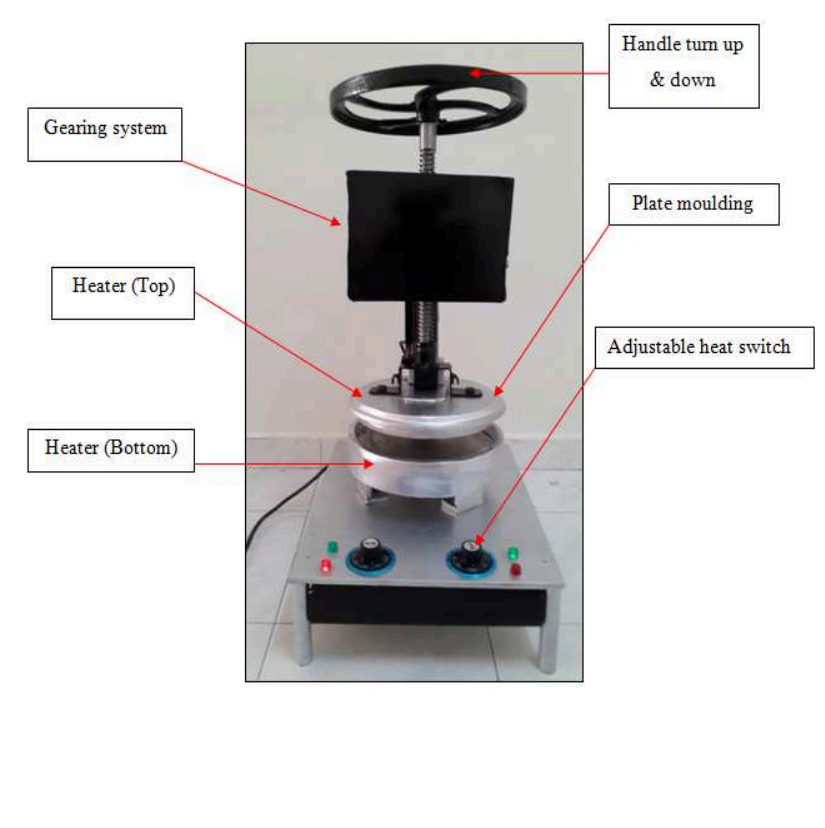

b)

Figure 1: a)Schematic Specimen preparation b) Hot press machine for disposable plate producing

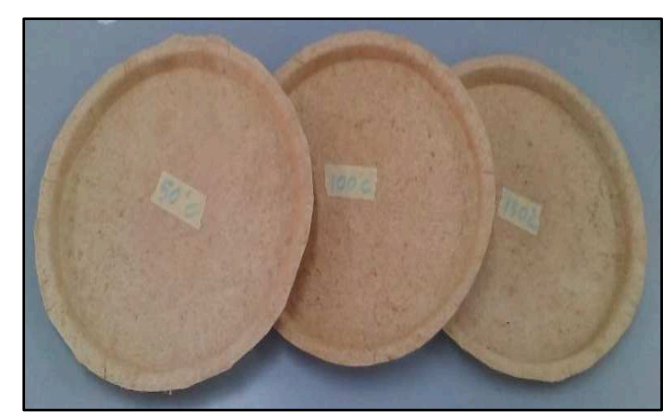

Figure 2: Sample disposable plates 


\section{Results and Discussion}

Higher density in natural fibers results in higher water moisture content which is a very important property that determine the general strength of the resulting paper products [9-10]. Fig. 3(a) shows the result of moisture content for two different samples. From the results, the moisture content was decreased when the composition of PALF/sugarcane changed to a higher PALF. Water absorption and their resulting effects contribute to the loss of compatibilization between fibers and matrices which results in debonding and weakening of the interface adhesion [11-14]. Density of fiber affects the rate of water absorption on the fiber as shown on Fig.3 (b). Fig. 4 shows that at the temperature of $150{ }^{\circ} \mathrm{C}$, the lowest percentage of water absorption occurs on specimen N8T2 which is $60.26 \%$. These indicate the higher temperature might be beneficial for PALF as compared to the bagasse. In addition, the increase of heat shows of the specimen changing circumstances of composition characteristic.

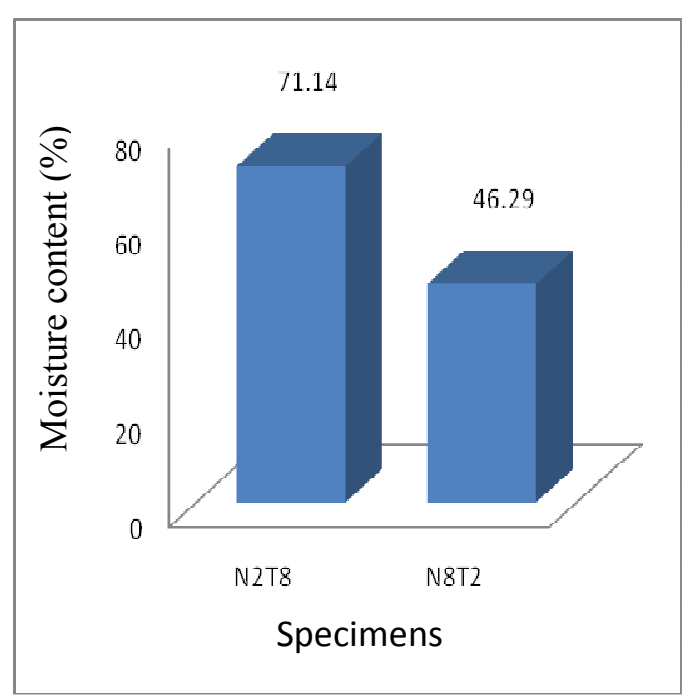

(a)

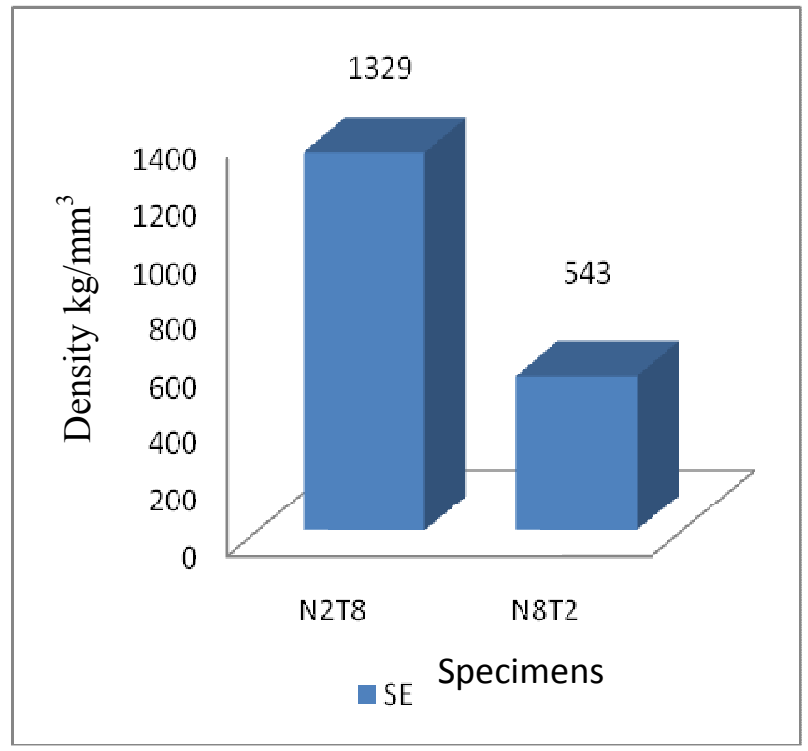

(b)

Figure 3: Effects of (a) moisture content (b) Effect of density on PALF/ sugarcane bagasse composition 


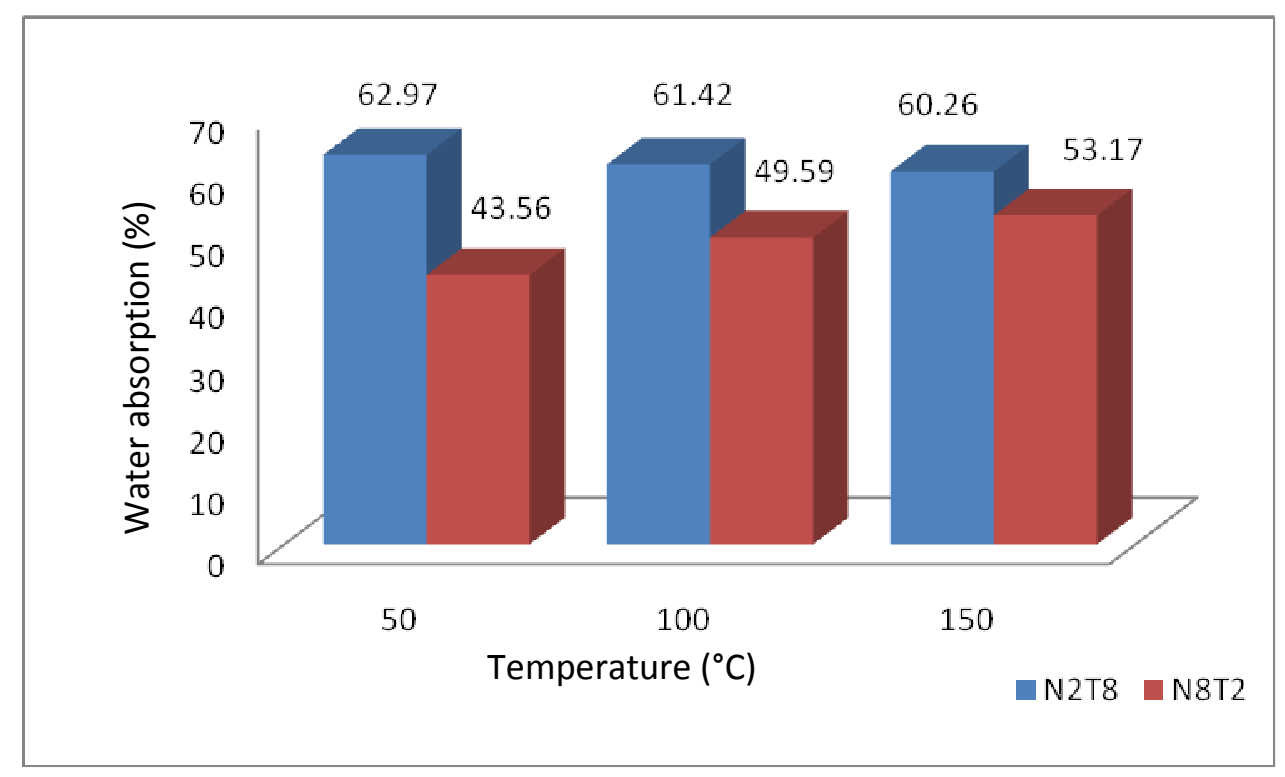

Figure 4: Effect of temperature on water absorption

\section{Conclusion}

This research work provides basic information on nature fiber development forms waste material for plate disposal. The presented work is related to the mechanical behavior and the effect of compression temperature for moisture content and water absorption has been conducted. The large composition of sugarcane bagasse waste in composite paper plate shows the moisture content, density and water absorption characteristic increasing. The PALF fiber type plate is more hydroscopic and water resistance than bagasse waste. The surface roughness was smooth on disposable plate at lowest PALF percentage. The higher heat treatment indicates the rough surface for the specimens.

\section{References}

[1] L. Jimenez, I. Perez, F. Lopez, J. Ariza and A. Rodriguez: Influence of the cooking and the beating of the pulps on the properties of the resulting paper sheets: Bioresource Technology Vol. 83 (2002), p. 139-143

[2] H.Q. Lam, Y.L. Bigot, M. Delmas and E.G. Avignon: Formic acid pulping of rice strawIndustrial Crops and Products Vol. 14 (2001), p. 65-71

[3] P. Rousu, R. Paivi and J. Anttila: Resources, Sustainable pulp production from agricultural Waste Coversation and Recycling Vol. 35 (2002), p.85-103

[4] Y. B. Seo, Y.W. Lee, C.H. Lee, H.C. You, Red Algae and their Use in Papermaking. Bioresource Technology, 101(2010) 2549-2553.

[5] N. Cordeiro, M.n. Belgacem, I.C. Torres and J.C.V.P. Moura: Chemical composition and pulping of banana pseudo-stems: Industrial Crops and Products Vol.19 (2004), p. 147-154

[6] A. Sbrilli, Strategy to Reduce Unintentional Production of Pops in China, Retrived May 01, 2002 from www.unido.org. (2007)

[7] M.P. Westman, L.S. Fifield, K.L. Simmons, S.G. Laddha, T.A. Kafentzis, Natural Fiber Composites: A Review, U.S. Department of Energy, Pacific Northwest National Laboratory (2010).

[8] S.P. McLaughlin, Properties of Paper Made From Fibers of Hesperaloe Funifera (Agavaceae) 1. Economic Botany 54-2(2000) 192-196. 
[9] M.S. Mustapa, S.D. Sabdin, E. Abdul Rahim, M.S. Wahab, Y. Yusof, Effect of Heat Compression on the Tensile Strength of PALF/Sugarcane Bagasse for Disposable Plate, Applied Mechanics and Materials, 660, 362 (2014)

[10] K.P. Chao, Y.C. Su, C.S. Chen, Feasibility Of Utilizing Rhizoclonium In Pulping And Papermaking. Journal of Applied Phycology 12: 53-62, 2000.

[11] J. George, S.S. Bhagawan, S. Thomas, Effects of Environment on the Properties of Lowdensity Polyethylene Composites Reinforced with Pineappleleaf Fiber. Composites Science and Technology. 58: 1471-1485. (1998)

[12] H.N Dhakal, Z.Y Zhang \& M.O.W. Richardson, Effects of Water Absorption on the Mechanical Properties of Hemp Fibre Reinforced Unsaturated Polyester Composites. (2006)

[13] Kritiina Oksman Niska \& Aji P Mathew. Natural Fiber Composites manufactured using long fiber Thermoplastic (LFT) Compounding and Compression moulding (2009)

[14] Q. Lin, X. Zhou, G. Dai, Effect of hydrothermal environment on moisture absorption and mechanical properties of wood flour-filled polypropylene composites, J Appl Polym Sci, volume 85 (14) pp. 2824-2832 (2002) 